\title{
Do Children Recognize That Kinship Relationships Have an Innate Biological Basis?
}

\author{
Lakshmi Raman $^{1}$ \\ ${ }^{1}$ Department of Psychology, Oakland University, Rochester, USA \\ Correspondence: Lakshmi Raman, Oakland University, Rochester, MI 48309, USA. Tel: 1-248-370-2302. E-mail: \\ raman@oakland.edu
}

Received: September 16, 2018

Accepted: October 18, 2018 Online Published: November 12, 2018

doi:10.5539/jedp.v9n1p1

URL: http://doi.org/10.5539/jedp.v9n1p1

I wish to thank my research assistants Jasmine Cosby, Lama Hodroj and Jennifer Ishaq for their assistance in the data collection. I would also like to thank the Director and the staff of Lowry Early Childhood Education Center for allowing me to conduct my study at their center.

\begin{abstract}
Three studies were conducted to investigate if four and five year old children recognize that kinship relationships are determined by biological associations and not environmental conditions. All three studies employed the "switched-at-birth" task. Study 1 investigated if children and adults recognize who the biological parents and siblings are. Study 2 examined preschoolers' and adults' recognition of who the biological parents and siblings are when step parents and step siblings were introduced into the family. Study 3 examined if children and adults extend their knowledge of kinship relationships to non-human creatures. For Studies 1 and 2, results indicated that preschoolers and adults have a robust and accurate biological model of kinship for both biological parents and sibling relationships. However in Study 3, preschoolers had a more difficult time recognizing biological sibling relationships than biological parent relationships in the presence of step parents and step siblings for non-human biological creatures. In totality, these results suggest that even young children (like adults) have a robust theory of kinship when reasoning about human relationships. However children's model of kinship is fragile and still developing when reasoning and extending their knowledge about humans to non-human species.
\end{abstract}

Keywords: children, innate biological basis, kinship relationships

\section{Introduction}

How do children reason about kinship relationships? Do preschoolers recognize that kinship relationships are biologically inherited irrespective of changing environmental conditions? This topic has both theoretical and practical importance. Theoretically, these studies enlighten us about children's underlying biological theories about family relationships and whether children recognize that individuals are related based on underlying biological ties even when physical appearances can be vastly different. Practically, the data from these studies will inform educators about the knowledge that children have about family relationships. This knowledge can be used to tailor age appropriate programs when explaining familial relationships to young children.

The following three studies examine if children recognize that kinship relationships are biological associations that result in social labels that do not change across varying environmental conditions. Kinship relationships are different from other biological processes such as height and weight that are influenced both by genetics and environmental factors. Study 1 examines if four and five year olds recognize parent and sibling relationships. Study 2 examines if four and five year olds recognize who the biological parents and siblings are when step parents and step siblings are introduced into the family. Study 3 examines if four and five year olds extend their knowledge of kinship relationships to non-human anthropomorphic species.

\subsection{Children's Understanding of Inheritance}

There is an extensive literature examining how children and adults reason about the role of inheritance in different biological domains such as growth, illness, physical characteristics and race (Raman, 2018; Raman \& Gelman, 2005; Solomon \& Cassamatis, 1999; Hirschfeld, 1995). Theoretically this topic is important as it speaks to a long-standing debate regarding how children first understand biological processes as distinct from psychological 
processes such as beliefs and desires.

Several studies have examined children's reasoning about the concept of inheritance in the areas of illness, race, internal physical properties and play preferences (Gelman \& Wellman, 1991; Hirschfeld, 1995; Raman \& Gelman, 2005; Springer, 1992; Springer \& Keil, 1989; Taylor, 1996). In a series of studies, Hirschfeld (1995) examined adult and grade school children's beliefs about inheritability of identity in mixed race children. Eight to twelve year olds and adults reasoned that mixed race children would more likely have black racial features and adults thought that these children would inherit the identity of the minority parent. Interestingly, children who attended an integrated school expected mixed race children to have intermediate racial features. Springer and Keil (1989) investigated children's intuitions about genetic transmission of features. They presented parent animals who possessed some abnormal internal/external, functional/non-functional features and children were asked if their offspring would have those abnormalities. Preschoolers reasoned that biological functional consequences were inherited much more frequently (similar internal organs) than social or psychological ones. These results suggest that preschoolers have biological notions of inheritance.

In the domain of other biological processes such as growth and illness, Raman (2018) investigated if children think that physical growth is determined primarily by genetics or an environmental factor such as nutrition. All three studies employed the "switched-at-birth" task. Results indicated that overall preschoolers and third graders reasoned that height was more strongly influenced by inheritance than weight. However, when nutrition was introduced, all other grades (apart from third graders) reasoned that nutrition played a greater role in determining weight. These results indicate that even young children have a rudimentary but differentiated theory of the role of inheritance in determining height and weight. In the domain of illness, Raman and Gelman (2005) found that even preschoolers could distinguish that genetic illnesses are primarily caused by inheritance compared to contagious illnesses. Preschoolers through fifth graders and adults were tested on "switched-at-birth" tasks for contagious and genetic illnesses. The results indicated that by the preschool years, children recognize that genetic illnesses are not transmitted through germ contagion but instead transmitted through kinship associations. Williams and Smith (2010) examined 4, 7, 10, and 14 year olds' naïve concepts of inheritance using a modified adoption task, a causal mechanism task and a family relatedness task. They found that there was a sequential acquisition of inheritance concepts and that later on biological inheritance concepts are consistently applied across different task contexts. However, there was no consistency in children's verbalized inheritance explanations and definitions. All of the above studies have demonstrated that young children recognize that certain non-perceptible properties are inherited from the biological parents and are not influenced by changing environmental conditions. However, as demonstrated by the Williams and Smith (2010) study, it is important to recognize that there is a developmental trend with older children performing better than the younger children (but see Solomon, Johnson, Zaitchik \& Carey, 1996 and Springer, 1996, for a debate).

Unlike some biological processes like illness, height and weight (which are influenced both by genetics and the environment), some biological associations (like kinship relationships) are determined completely by genetic associations that give rise to social labels. In a series of studies, Springer (1996) examined if kinship relationships imply but do not guarantee similarity among family members. Study 1 examined if preschoolers recognize that adopted babies resemble their biological parents and not their adoptive parents. Study 2 examined if children realized that physical resemblance and long-term proximity between an adult and child do not guarantee a biological link. Springer found that preschoolers expected children and offspring to share physical properties but they also recognized that shared properties do not guarantee kinship relationships. These results suggest that young children attribute kinship to internal biological processes (where the baby grows) and not to the social environmental factors. In another study, Springer (1992) explored children's understanding of kinship relationships by presenting a target animal. The target animal was described as possessing a property and children were asked if two other animals possessed the same property. When no kinship information was presented, preschoolers reasoned that similar looking characters were related. However, when kinship information was presented, children judged that dissimilar looking kin (as opposed to similar looking but non-related kin) possessed similar biological properties. These results again demonstrate that young children relate a non-perceptible relationship over a perceptible one when making judgments about biological relatedness. Spokes and Spelke (2016) investigated how 3-5 year old children understand kinship relationships in comparison to non-kin relations between friends in a storybook context and in a richer context that presented kinship cues using face morphology. Three-4 year olds did not show any conceptual distinction between kin and friends or expecting to favor one group over the other. However by age 5, children showed some expectation that people will aid siblings over friends demonstrating a developmental trend over the preschool years.

The review of the above literature suggests that by the end of the preschool years, children recognize that 
underlying biological relationships as opposed to environmental factors determine kinship relationships. However, there has been no research that has examined if children can accurately infer and integrate kinship relationships based on social labels such as (mother, father, sister, etc.).

The following three studies used a modified "switched-at-birth" task (Hirschfeld, 1994) to study children's recognition of kinship relationships. In a typical switched-at-birth task, participants are presented with vignettes that describe two sets of parents whose babies are accidentally switched at birth. The birth parents and the adoptive parents differ on some crucial dimensions. The point of interest in the current studies is whether participants accurately infer the kinship relationships based on the description in the vignette. Study 1 examines if preschoolers and adults can accurately identify who the parents and siblings are based on biological associations. Study 2 examines if children and adults can accurately identify the biological parent and sibling relationships based on stepparent and stepsibling family relationships. Study 3 examines if children extend kinship labels and relationships to non-human alien creatures.

\section{Study 1}

Although previous studies have demonstrated that children recognize the underlying kinship relationships in biological relationships, the question this study examines is whether children recognize who their kin are based on social labels. The following study presents scenarios where a couple has a child and in certain cases participants are asked who the parents are and in other cases they are asked who the siblings are. Based on Springer (1992; 1996) we would expect children to be able to identify who the parents/siblings are based on the social labels.

\subsection{Participants}

Twenty-one preschoolers ( 13 females and 8 males; $\mathrm{M}$ age $=4$ years 8 months; range $=4$ years 1 month to 5 years 5 months) and 24 adults ( 21 females and 3 males; $\mathrm{M}$ age $=22$ years and 6 months; range $=19$ years 5 months to 24 years 2 months) were recruited from preschools in a small Midwestern city in the United States and adult participants were part of an undergraduate subject pool at a large Midwestern university. Participants had to be fluent in English to be able to participate in the study. Participants who took part in one study did not participate in any of the other studies.

\subsection{Materials and Methods}

There were a total of 8 vignettes. Four of the vignettes were on parental relationships and the other 4 vignettes were on sibling relationships. Each of the participants received all of the 8 vignettes. The presentation of the response choices was counterbalanced and the vignettes were randomized for each of the participants.

\subsection{Procedure}

Children were interviewed individually. They were shown line drawings of the parents for each of the vignettes to hold the child's attention but not to provide any more additional information regarding the appearance of the character. The child/children in the vignettes were not shown in the drawings. The experimenter read the vignettes to the children, pointing to the relevant drawings when reading the vignettes. The child was then asked to respond verbally and the experimenter wrote down the child's responses. Adults were also tested individually in an identical fashion to the preschoolers. An example of a vignette that was used for the parental condition was the following:

Mr. and Mrs. Corby had a baby boy. That means that the baby boy came out of Mrs. Corby's tummy. They named the baby boy Jordan. After a long time, Mr. and Mrs. Corby had another baby. She was a girl and they named her Anne.

(a) Whose tummy did Jordan come out of?; (b) Whose tummy did Anne come out of?; (c) Who is Jordan's mother?; (d) Who is Jordan's father?; (e) Who is Anne's mother?; (f) Who is Anne's father?

An example of a vignette that was used for the sibling condition was the following:

Mr. and Mrs. Ezra had a baby boy. That means that the baby boy came out of Mrs. Ezra's tummy. They named the baby boy Cullen. After a long time, Mr. and Mrs. Ezra had another baby. She was a girl and they named her Sara.

(a) Whose tummy did Cullen come out of?; (b) Whose tummy did Sara come out of?

(c) Who is Sara's brother?; (d) Is (child's answer) Sara's big brother or little brother?

\subsection{Coding}

Only participants who passed the memory questions (whose tummy did (the name of the child) come out of) were 
included in the final analyses for the study. If participants identified the correct parent or sibling, their responses were scored as ' 1 ', if they got the response incorrect, their responses were scored as ' 0 '.

\subsection{Results}

Comparison of the means for the parental responses revealed that both preschoolers and adults performed at ceiling for both the parental responses and the sibling responses $(\mathrm{Ms}=4.0$ and 4.0 for parental responses for preschoolers and adults respectively; Ms $=4.0$ and 4.0 for sibling responses for preschoolers and adults respectively). All means were out of a maximum of 4.0. These results indicate that 4 and 5 year olds have a solid recognition of biological parental and sibling relationships like adults do.

\subsection{Discussion}

The results of this study demonstrate that four and five year olds make biological associations of parental and sibling relationships. This demonstrates that they seem to be able to make a biological attribution for parental and sibling relationships and that they make the appropriate gender distinction when reasoning as to who the mother and who is the father. However, in order for us to be confident that children reason about kinship relationships based on biological relatedness and not environmental factors, we need to be examine if children make kinship associations based only on proximity or if they recognize that these kinship relationships can be maintained across distance and time. Study 2 examines this concept by presenting children with biological and step parent and step sibling scenarios to determine if children recognize that their biological siblings are their siblings related by kin, even though their step siblings live with them.

\section{Study 2}

Study 1 established that preschoolers clearly recognize the parental and sibling relationship between their biological parents and biological siblings. Study 2 examines if four and five year old children recognize that step parents and step siblings are not their real biological parents/siblings. Based on previous findings (Springer, 1996) that have argued for the notion that children make internal biological attributions on inheritance, we would expect children to recognize that their biological siblings are their 'real' siblings even if they are not proximally close.

\subsection{Participants}

Twenty-four preschoolers ( 15 females and 9 males; $\mathrm{M}$ age $=4$ years 4 months; range $=4$ years to 5 years 1 month) and 20 adults ( 10 females and 10 males; $M$ age $=23$ years 9 months; range $=18$ years to 24 years 5 months) were recruited from preschools in a small Midwestern city in the United States and adult participants were part of an undergraduate subject pool at a large Midwestern university. Participants had to be fluent in English to participate in the study.

\subsection{Materials and Methods}

There were a total of 8 vignettes that examined participants' understanding of step mother, step father, step brother and step sister relationships. There were two vignettes on each of these relationships. Each of the participants received all of the 8 vignettes. The presentation of the response choices was counterbalanced and the vignettes were randomized for each of the participants.

\subsection{Procedure}

The procedure was identical to that of Study 1. Participants were shown line drawings of all characters for each of the vignettes to hold the child's attention but not to provide any more additional information regarding the appearance of the character. An example of a vignette that was used for the step mother condition was the following:

Mr. Smith and Mrs. Smith had a baby. The baby came out of Mrs. Smith's belly. They named the baby Lucy.

1. Who is Lucy's father? Mr. Smith or Mrs. Smith?

2. Who is Lucy's mother? Mr. Smith or Mrs. Smith?

Soon after Lucy was born, Mrs. Smith moved into a new house. After Mrs. Smith moved, another woman, Mrs. Jones came to live with Mr. Smith and Lucy. Mrs. Jones took good care of Lucy and brushed her hair every night and kissed her good night. Who is Lucy's mother? Mrs. Smith or Mrs. Jones.

\subsection{Coding}

Only participants who passed both of the memory questions (whose tummy did (the name of the child) come out of) were included in the final analyses for the study. If participants identified the correct biological parent or sibling, their responses were scored as ' 1 ', if they got the response incorrect, their responses were scored as ' 0 '. 


\subsection{Results}

A 4 relationship (stepmother; stepfather; stepbrother; stepsister) x 2 grade (preschool; adults) repeated measures ANOVA was conducted with the type of relationship selected as the dependent variable and grade as the between subjects variable. There was no main effect for relationship $\mathrm{F}(1,42)=.28, \mathrm{p}>.5$, or relationship x grade, $\mathrm{F}(1,42)$ $=.28, \mathrm{p}>.5, \eta_{\mathrm{p}}{ }^{2}=.89$, but there was a significant grade interaction, $\mathrm{F}(1,43)=11.3, \mathrm{p}<.002$.

Table 1. Means (out of a maximum of 4 for each category) for parent and sibling relationships across grade for Study 2. () indicates S.D.s.

\begin{tabular}{lll}
\hline Grade & Parents & Siblings \\
\hline Preschool & $2.21(1.6)$ & $2.42(1.5)$ \\
Adults & $3.60(1.2)$ & $3.60(1.2)$ \\
\hline
\end{tabular}

\subsection{Discussion}

The goal of this study was to determine if four and five year olds recognize that their biological siblings and parents are their 'real' siblings or parents (even if they are separated by distance). The results indicate that they perform as well as adults do by recognizing that biological siblings and parents do not have to be in close proximity in order for children to recognize that they are related by kin. Similarly, they do not reason that stepsiblings are their 'real' siblings because they live in the same house. These results suggest that even young children make biological attributions based on kinship connections and not on external environmental factors such as proximity. However, adults performed significantly better across both tasks compared to children.

One of the questions that this study raises is whether children can generalize their biological theory of kinship to other non-human creatures. If they can do this, this would illustrate that children can apply their theory of kinship to other living species and that their theory is not limited to humans. This possibility is explored in Study 3 by presenting participants with alien like creatures involved in the same family relationships as those that are described in this study.

\section{Study 3}

The results of studies 1 and 2 illustrate that preschoolers have a solid understanding of biological family relationships. However, in order for us to be confident that children have a robust theory of kinship, children should also be able to apply their knowledge to non-human living species. In this study, we will examine the same family relationships as those of Study 2 with the exception that we will be presenting non-human species to determine if four and five year olds can appropriately apply their kinship knowledge of humans to these creatures.

\subsection{Participants}

Twenty-four preschoolers $(12$ females and 12 males; $M$ age $=4$ years 10 months; range $=4$ years 6 months to 5 years 3 months and 28 adults ( 23 females and 5 males; $M$ age $=21$ years and 6 months; range $=19$ years 3 months to 22 years 8 months) were recruited from preschools in a small Midwestern city in the United States and adult participants were part of an undergraduate subject pool at a large Midwestern university. Participants had to be fluent in English to participate in the study.

\subsection{Materials and Methods}

There were a total of 8 vignettes that examined participants' understanding of step mother, step father, step brother and step sister relationships. There were two vignettes on each of these relationships (resulting in a total of 8 vignettes). Each of the participants received all of the 8 vignettes. The presentation of the response choices was counterbalanced and the vignettes were randomized for each of the participants.

\subsection{Procedure}

The procedure was identical to that of Studies 1 and 2. Participants were shown line drawings of alien characters for each of the vignettes to hold the child's attention but not to provide any more additional information regarding the appearance of the character.

Mr. and Mrs. Droo had a little girl named Sarah. That means Sarah came from Mrs. Droo's tummy. Right after Sarah came out of Mrs. Droo's tummy, Mrs. Droo went to go live in another cave. After Mrs. Droo left another creature Ms. Flax came to live with Mr. Droo. Ms. Flax was very nice to Sarah and she took care of her. Who is Sarah's mother? (a) Ms. Droo; or (b) Ms. Flax? 


\subsection{Coding}

Only participants who passed the memory questions (whose tummy did (the name of the creature) come out of) were included in the final analyses for the study. If participants identified the correct biological parent or sibling, their responses were scored as ' 1 ', if they got the response incorrect, their responses were scored as ' 0 '.

\subsection{Results}

A 4 relationship (stepmother; stepfather; stepbrother; stepsister) x 2 grade (preschool; adults) repeated measures ANOVA was conducted with the type of relationship selected as the dependent variable and grade as the between subjects variable. There was a main effect for relationship $\mathrm{F}(1,50)=13.43, \mathrm{p}<.01, \eta_{\mathrm{p}}{ }^{2}=.08$, and a significant relationship x grade interaction, $\mathrm{F}(1,50)=4.43, \mathrm{p}<.043, \eta_{\mathrm{p}}{ }^{2}=.21$. There was no significant grade effect, $\mathrm{F}(1,50)$ $=1.1, \mathrm{p}>.3, \eta_{\mathrm{p}}^{2}=.02$.

Table 2. Means (out of a maximum of 4 for each category) for non-human parent and sibling creature relationships across grade for Study 3

\begin{tabular}{lll}
\hline Grade & Parents & Siblings \\
\hline Preschool & $3.21(1.3)$ & $2.42(1.6)$ \\
Adults & $3.32(1.4)$ & $3.11(1.5)$ \\
\hline
\end{tabular}

Note. ( ) indicates S.D.s.

\subsection{Discussion}

The goal of this study was to determine if four and five year olds would extend their knowledge about kinship relationships in humans to other non-human creatures. If indeed children can extend their knowledge of human kinship relationships to non-human creatures, this would present a more convincing argument that young children have a robust theory of kinship.

The results of this study demonstrate that overall participants perform better on the stepparent relationships compared to the stepsibling relationships. There is also a grade difference with adults performing better than children on the sibling questions than the parent questions but overall there was no significant difference between the two age groups in their participation across the task. These results suggest that children have a more difficult time determining sibling relationships for non-human anthropomorphic creatures than they do for parent relationships with these creatures. This also indicates that there might be a developmental pattern in children's learning about kinship relationships, with children learning about biological parental relationships before sibling relationships.

There could be a couple of explanations for this developmental pattern. First, an earlier recognition of parental relationships than sibling relationships would help maximize the chances of survival of the children (since parents (not siblings) are the primary caregivers of children). Second, children for the most part learn parental labels such as 'mommy', 'daddy' before they learn the names of their siblings, thus it might be easier to recognize parental relationships before sibling relationships.

\section{General Discussion}

The objective of these studies is to determine if four and five year olds recognize that kinship relationships are based on biological ties and not depend on external appearances, location or proximity. Unlike previous studies in the area of inheritance that have examined children's understanding of illness, internal physical properties and race (Raman, 2014; Raman, 2017; Wellman \& Johnson, 1982) these studies examine if children recognize their biological parents and siblings based on social labels that kinship relationships create. Studies 1 and 2 clearly illustrate that four and five year olds have a solid recognition of who their biological parents and siblings are even when presented with situations where step parents and step siblings are living with them and performing the same roles as biological parents and biological siblings would (caring for the child, playing with him/her, etc.). This suggests that young children are not relying on external superficial cues such as proximity or the roles that the parents or siblings are playing to determine who their biological parents and siblings are. Study 3 however demonstrates a developmental trend with children having a more difficult time than adults in determining who the biological siblings were when they were presented with non-human anthropomorphic creatures. Interestingly, they did not have as much of a difficulty in identifying who the biological parents are. This developmental trend can be explained from an evolutionary perspective since the biological parents are usually the primary caregivers and they 
maximize the survival of the child. Thus, being able to identify who the biological parents are before the biological siblings helps ensure survival.

The results of the three studies suggest that by the end of the preschool years, children's biological model of kinship relationships is highly developed and based on biological associations and not on external factors. However, the results from Study 3 also demonstrates a developmental aspect of children's recognition of kinship relationships by demonstrating that children have a more difficult time with sibling relationships than parental relationships with non-human creatures. This suggests that their recognition of kinship relationships in general is still fragile and developing compared to that of adults when applying their knowledge to non-human creatures.

There are a few limitations to these studies. First, although the demographic information of race and ethnicity was not collected from participants, the majority of our participants came from White middle class families who in turn could limit the generalizability of these results to this population. Second, kinship labels such as 'mother', father' can be used to refer to non-biologically related members ('she is like a mother to me'). While this inference was probably too complicated for four and five year olds to process, adults could have inferred that the reference was to the term 'mother' or 'father' in general and not to the biological mother or father. This might also explain why in Study 2, adult responses were not at ceiling level.

There are several avenues for future studies in this area. First, these studies should be conducted with populations that are more ethnically diverse. Second, future studies should make it clear that the vignettes are referring to the biological parents and biological siblings. Some participants (especially adults) might not be viewing the mother/father, brother/sister labels as referring to biological kinship relationships. Third, it would also be interesting to conduct these studies with 3 year olds to determine if there is a developmental difference in their ability to recognize biological parents and biological siblings relationships. Recall that four and five year olds did not have difficulty with parent and sibling relationships but they were not able to extend this knowledge effectively for sibling relationships for non-human creatures in Study 3. Testing 3 year olds would give us a window as to when children's understanding of biological parental and sibling relationships emerge. Similarly, testing older children would reveal when children can accurately generalize kinship relationships to other non-human species.

In conclusion, the results of these studies demonstrate that young children's kinship model is sophisticated and more differentiated than previously reported. However, their theory of kinship is still fragile and developing when they are extending their knowledge to non-human anthropomorphic creatures.

\section{Acknowledgments}

I am grateful to the parents, teachers and staff of Lowry Early Childhood Education Center for participating in this study.

\section{Conflict of Interest Statement}

The author declares that there is no conflict of interest regarding the publication of this paper.

\section{References}

Gelman, S. A., \& Wellman, H. M. (1991). Insides and essences: Early understandings of the non-obvious. Cognition, 38, 213-244. https://doi.org/10.1016/0010-0277(91)90007-Q

Hirschfeld, L. A. (1995). Do children have a theory of race? Cognition, 54, 209-252. https://doi.org/10.1016/0010-0277(95)91425-R

Hirschfeld, L. A. (1994). Is the acquisition of social categories based on domain-specific competence or on knowledge transfer. Mapping the mind: Domain specificity in cognition and culture, 201-233. https://doi.org/10.1017/CBO9780511752902.009

Raman, L. (2018). Do children think that inheritance determines height and weight? Infant and Child Development. https://doi.org/10.1002/icd.204.

Raman, L. (2014). Children's and adults' understanding of the impact of nutrition on biological and psychological processes. British Journal of Developmental Psychology, 32, 78-93. https://doi.org/10.1111/bjdp.12024

Raman, L., \& Gelman, S. A. (2005). Children's understanding of the transmission of genetic disorders and contagious illnesses. Developmental Psychology, 41, 171-182. https://doi.org/10.1037/0012-1649.41.1.171

Solomon, G. E., \& Cassamatis, N. (1999). On facts and conceptual systems: Young children's integration of their understanding of germs and contagion. Developmental Psychology, 35, 113-126. https://doi.org/10.1037/0012-1649.35.1.113 
Solomon, G. A., Johnson, S. C., Zaitchik, D., \& Carey, S. (1996). Like father like son: Young children's understanding of how and why offspring resemble their parents. Child Development, 67, 151-171. https://doi.org/10.2307/1131693

Springer, K. (1996). Young children's understanding of the biological basis of parent-offspring relations. Child Development, 67, 2841-2856. https://doi.org/10.2307/1131755

Springer, K. (1992). Children's awareness of the biological implications of kinship. Child Development, 63, 950-959. https://doi.org/10.2307/1131246

Springer, K., \& Keil, F. C. (1989). On the development of biologically specific beliefs: the case of inheritance. Child Development, 60, 637-648. https://doi.org/10.2307/1130729

Spokes, A. C., \& Spelke, E. S. (2016). Children's expectations and understanding of kinship as a social category. Frontiers in Psychology, 7, article 440.

Taylor, M. G. (1996). The development of children's beliefs about social and biological aspects of gender differences. Child Development, 67, 1555-1571. https://doi.org/10.2307/1131718

Williams, J. M., \& Smith, L. A. (2010). Concepts of kinship relations and inheritance in childhood and adolescence. British Journal of Developmental Psychology, 28, 523-546. https://doi.org/10.1348/026151009X449568

\section{Copyrights}

Copyright for this article is retained by the author(s), with first publication rights granted to the journal.

This is an open-access article distributed under the terms and conditions of the Creative Commons Attribution license (http://creativecommons.org/licenses/by/4.0/). 